\title{
EL PASADO EN EL PRESENTE: LAS MORADAS DE "LOS ANTIGUOS" EN LA COSMOLOGÍA MAYA PENINSULAR ACTUAL
}

\author{
David de Ángel García \\ Centro Peninsular en Humanidades y Ciencias Sociales, UNAM
}

\begin{abstract}
Resumen: A lo largo del presente escrito se pretende ofrecer un somero acercamiento de carácter etnográfico al papel que desempeñan los restos arqueológicos del pasado maya prehispánico (cuyos) en la cosmología de los indígenas peninsulares contemporáneos, de manera especial entre aquellos que habitan la región norte del Camino Real de Campeche.

Tomando como punto de partida los testimonios de varios informantes, me centraré en el papel de los cuyos como espacios habitados por un buen número de entidades sagradas, todas ellas profundamente vinculadas con los antiguos pobladores del mayab, y como lugares a donde los h-meno' ob locales (especialistas rituales) acuden en busca de los poderes y conocimientos que les permitirán desempeñar sus funciones como intermediarios entre hombres y divinidades.
\end{abstract}

PAlABRAS Clave: etnografía, mayas peninsulares, cuyos, deidades del monte, $h$-meno'ob.

ABSTRACT: In this paper I will offer a brief ethnographic overview of the role archaeological ruins (known as cuyos) play in the worldview of indigenous groups from the Peninsula of Yucatan, and in particular, of those inhabiting the region North of the Camino Real in Campeche Using as evidence the oral testimony from various informants, I will focus on the function of these cuyos as spaces inhabited by a number of sacred entities who are profoundly linked to the ancient population of the Mayab. I will also explore the relationship these sacred spaces have with the local h-meno'ob (ritual specialists) who seek them out as seats of power and knowledge, in order to carry out their functions as intermediaries between men and divinities.

KEYwords: ethnography, peninsular Maya, cuyos, gods of the forest, $h$-meno'ob.

RECEPCIÓN: 26 de marzo de 2013.

ACEPTACIÓn: 23 de agosto de 2013. 



\title{
EL PASADO EN EL PRESENTE: LAS MORADAS DE "LOS ANTIGUOS" EN LA COSMOLOGÍA MAYA PENINSULAR ACTUAL
}

\author{
DAVID DE ÁnGEl García \\ Centro Peninsular en Humanidades y Ciencias Sociales, UNAM
}

El presente trabajo se aboca a la descripción etnográfica de un pequeño fragmento del complejo cosmogónico de los mayas peninsulares que habitan actualmente en la comunidad de Nunkiní y algunas rancherías aledañas (Tankuché, Santa Cruz Exhacienda, Pucnachén), situadas todas ellas en el municipio de Calkiní, al norte del estado de Campeche, en el corazón de la microrregión cultural llamada Camino Real. ${ }^{1}$ Me ocuparé, más concretamente, de un conjunto de prácticas y creencias que, a priori, podríamos considerar alejadas de la tradición cultural ibérica y que, por tanto, deberían ser catalogadas como esencialmente amerindias. Con esta afirmación no pretendo insinuar que las dos tradiciones culturales apuntadas, la nativa y la hispana colonial, se encuentren diferenciadas y separadas entre sí en el actuar cotidiano de los miembros de la etnia maya peninsular. Muy al contrario, recurriendo a las palabras de Manuel Gutiérrez Estévez, podemos decir que "ambas tradiciones se encuentran amalgamadas en un único sistema cultural que proporciona significado a la vida personal y colectiva" de la población indígena de la península de Yucatán (1992a: 419).

Así, estos dos conglomerados de usos, prácticas, creencias y costumbres de procedencias tan dispares son empleados de manera indiferenciada e inconsciente por los actores sociales durante el transcurso de sus vidas, tanto en el actuar individual como en el colectivo. ${ }^{2}$ Sin embargo, conviene subrayar que

\footnotetext{
${ }^{1}$ Varios son los investigadores que han propuesto divisiones de la península de Yucatán en regiones o áreas culturales (Ruz, 2002a, 2006 y Quintal et al., 2003a), para algunas de las cuales han señalado incluso la existencia de subdivisiones internas. Éstas divisiones obedecen a las diversas características geográficas, poblacionales, económicas, sociopolíticas y culturales, así como a los divergentes procesos históricos que ha vivido la Península en su conjunto, lo que ha dado como fruto una cierta regionalización del espacio referido (Ruz, 2006). Según Ella F. Quintal, la población que habita la microrregión del Camino Real se caracteriza por tener en la agricultura de milpa, la horticultura, la producción de artesanías y el trabajo migratorio sus principales "estrategias de vida", amén de "conservar un elevado porcentaje de hablantes de lengua maya [...], y un apego especial a sus rituales y ceremonias 'ancestrales”' (2003a: 300).

${ }^{2}$ Cuando abordamos temas como el de la cosmovisión o la religiosidad entre los mayas yucatecos, podemos hablar de la existencia de representaciones colectivas en la medida en que las nociones de carácter individual presentan muy pocas variaciones en relación con las de la colectividad (Alicia M. Barabas, 2003: 17).
} 
con el correr de los siglos distintos componentes de estas visiones del mundo (la ibérica y la maya) ha ido sufriendo adecuaciones en función de las nuevas realidades en las que han debido insertarse. Ello, en mayor o menor medida, ha ido dando lugar a transformaciones, reelaboraciones, asimilaciones y resignificaciones tanto en el contenido de sus programas primigenios como en sus formas de significar el mundo circundante. En este sentido, comparto los postulados de Alfredo López Austin cuando subraya el carácter de "hecho histórico" que posee el complejo cosmológico y religioso mesoamericano, temáticas ambas en las que se inscribirá el presente trabajo. El autor mencionado, al abordar el carácter de las religiones indígenas mesoamericanas actuales, argumenta que el problema no es dilucidar si la religión prehispánica tuvo tanta fuerza que sus creencias han permanecido inalterables hasta la fecha o si, al contrario, la llegada del catolicismo volvió inapropiada cualquier comparación entre las concepciones religiosas del pasado y del presente (López Austin, 1994: 11). Muy al contrario, su visión trata de guardar una distancia prudente respecto a ciertos maniqueísmos academicistas al concluir que "las religiones actuales no son, evidentemente, una nueva versión del pensamiento y de las prácticas prehispánicas; pero, pese a la fuerte influencia del cristianismo, forman parte de la antigua tradición mesoamericana" (López Austin, 1994: 11).

Mucho, y bien, se ha escrito y discutido acerca del carácter mestizo, puro, híbrido, sincrético o dual de las actuales religiones mesoamericanas; ${ }^{3}$ por ello considero oportuno abandonar este tema y desplazarnos, al menos imaginariamente, al ejido de Nunkiní para tratar de conocer y desenmarañar una parte de la tupida red de significados que sus pobladores han tejido en torno a los vestigios arqueológicos que, por docenas, les rodean. La riqueza y complejidad simbólica que encierran en su interior estos montículos de piedras cubiertos de vegetación se hacen patentes desde el momento en que constatamos la enorme cantidad de términos que existen en el hablar cotidiano de los mayas peninsulares para hacer referencia a ellos. Así, en su idioma nativo, los vecinos de Nunkiní emplean indistintamente los vocablos múul o kaká para nombrar genéricamente a las elevaciones artificiales del terreno que salpican el paisaje habitado y el entorno natural de su comunidad. Asimismo, al expresarse en castellano utilizan alternativamente términos como los de "cerro" (o "cerrito"), "montículo", "elevación", "ruinas" o, el más empleado de todos ellos, "cuyo". ${ }^{4}$ Este último encierra en su etimología el carácter polisémico y eminentemente sagrado que todavía en la actualidad envuelve el espacio al que remite. Y es que la palabra cuyo parecería ser

\footnotetext{
${ }^{3}$ Referentes en este debate conceptual en torno las religiones amerindias resultan, entre otros, los escritos de García Canclini (2001), Gutiérrez Estévez (2002) y Lupo (1996).

${ }^{4}$ En esta ocasión escribo cuyo entrecomillado por remitir directamente a las fórmulas que emplean mis informantes para referir a las elevaciones del terreno que contienen restos del pasado. En adelante escribiré simplemente cuyo por tratarse de una palabra que, aún teniendo su origen en el término maya $k^{\prime} u u$, ha sido castellanizada y profusamente empleada por los primeros conquistadores ibéricos (como Bernal Díaz) desde su arribo a tierras continentales americanas.
} 
el resultado de la castellanización del vocablo maya $k^{\prime}$ 'uо'ob, plural de $k^{\prime} u u$, que, según el Calepino de Motul elaborado por fray Antonio de Ciudad Real a fines del siglo xvi, servía para referirse tanto a lo "sagrado" como a la "divinidad" (1995: 433-436). En esta misma dirección, el exhaustivo Diccionario maya de Alfredo Barrera Vásquez refiere que tanto la palabra $k^{\prime} u$ como su derivada $k^{\prime} u$ 'il remiten no sólo a Dios y a deidad indistintamente, sino también a "las casas y los templos" en los que se les adoraba, incluyendo en este rubro a las "pirámides antiguas", los "templos" y los "adoratorios" (2001: 416). ${ }^{5}$ Como veremos con base en las evidencias etnográficas, el carácter de receptáculo de lo sagrado y poderoso al que remitía el término $k^{\prime} u$ al arribo de las huestes españolas a tierras del mayab se ha mantenido vigente hoy en día en el arsenal de creencias y rituales que, en relación o dedicados a los moradores de los montículos arqueológicos, observan los indígenas peninsulares. ${ }^{6}$

Para centrarnos en lo que acontece en nuestra comunidad objeto de estudio, conviene apuntar desde un inicio que ésta constituye, en lo que se refiere a la relación que establecen sus habitantes con los cuyos, un caso paradigmático: tanto por el inusualmente elevado número de montículos que se cuentan en el interior de sus territorios ejidales, como por el destacado papel que éstos desempeñan en diversos ámbitos de su cosmovisión. En un intento por dotar de cierto orden a mi exposición, voy a centrarme aquí únicamente en dos aspectos concretos, cuyo nexo de unión será la estrecha vinculación que guardan ambos con esos espacios extraordinarios del pasado que, en la visión del mundo de los vecinos de Nunkiní, aparecen dotados de una densa y heterogénea carga simbólica. Así, en un primer momento me abocaré a la descripción de algunas de las "entidades poderosas" que radican en el interior de los restos arqueológicos para, una vez identificadas, tratar de señalar cuáles son sus principales atribuciones y características. A caballo entre este apartado y el siguiente presentaré algunas referencias a las formas más habituales que emplean los humanos para relacionarse con estas entidades sobrenaturales y, en base a ello, tratar de ilustrar la naturaleza sagrada que aquellos les suponen. En el segundo apartado del escrito abordaré, someramente, el trascendental papel que desempeñan los restos del pasado en la iniciación y en el trabajo ritual que llevan a cabo en la actualidad

\footnotetext{
${ }^{5}$ Siguiendo esta línea, en el volumen III del Diccionario etnolingüístico del idioma maya yucateco colonial, realizado por Cristina Álvarez, se consigna que la palabra $k u$ se empleaba por los mayas de la época colonial para referirse a "Dios" y a "las pirámides antiguas o lugares de adoración de los indios gentiles", mientras que el término ku yen designaba a una cosa divina o algo "sagrado, santo" (1997: 583).

${ }^{6}$ La creencia en torno a los vestigios arqueológicos de los mayas peninsulares como espacios sagrados ha sido registrada desde hace mucho tiempo. Así, en 1861, Carrillo y Ancona menciona con bastante desprecio cómo durante una visita que realizó a un "adoratorio" prehispánico en ruinas que se encontraba en la población de Motul (Yucatán), descubrió cómo los nativos realizaban en él ofrendas periódicas de balché, saka' y aves a los "genios y divinidades" que lo habitaban. El nombre que recibían estos rituales de ofrendas, según el autor, era tichh y resultaba común su realización allá donde había "ruinas encantadas" (1861: 300).
} 
los $h$-meno' $o b^{7}$ o especialistas rituales de la comunidad. Los cuyos serán, pues, el nexo de unión de las siguientes páginas, y la coartada perfecta para tratar de indagar en una parte de la cultura nativa que, aunque remite a tiempos pretéritos, se ha mantenido viva en el presente y, a su vez, viene a condicionar de manera importante la supervivencia de los mayas de Nunkiní en el futuro inmediato.

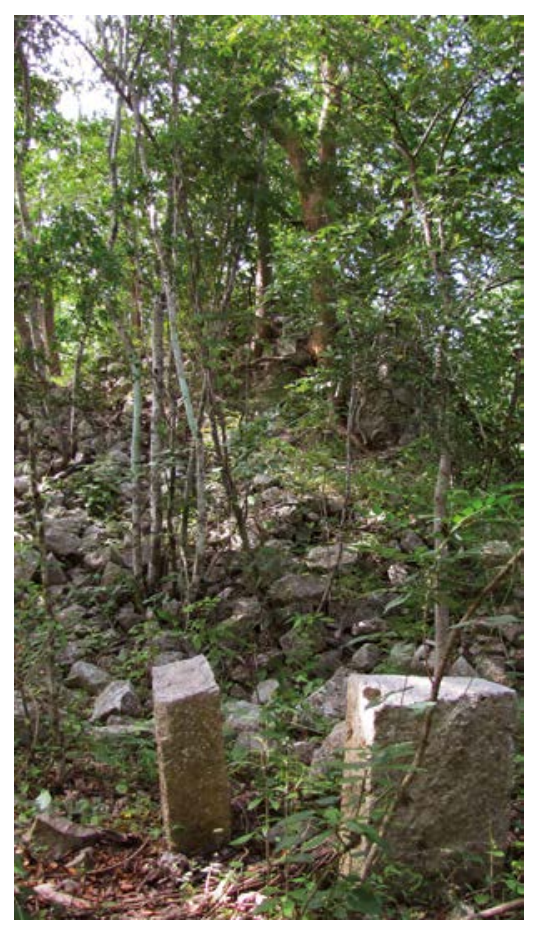

Figura 1. Imagen exterior de un cuyo en las cercanías de Nunkiní. Fotografía del autor.

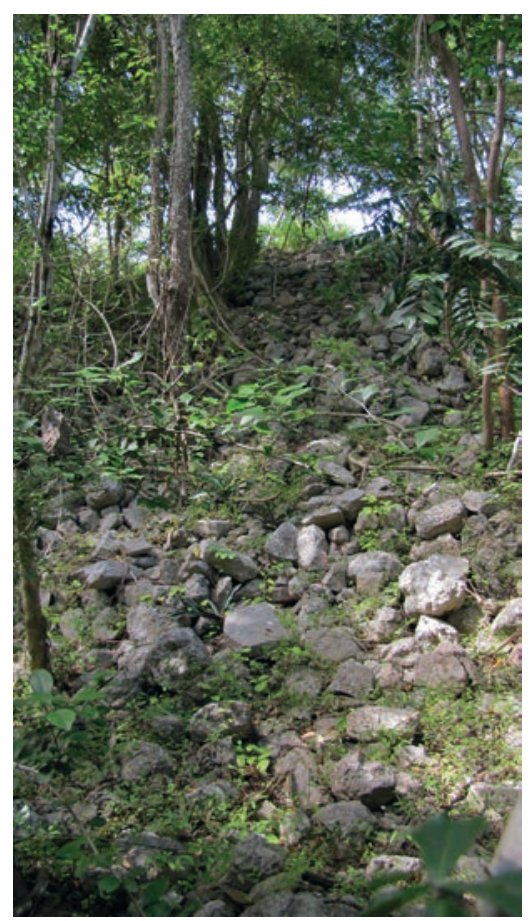

Figura 2. Los cuyos son acumulaciones de piedra cubiertas por una densa maleza. Fotografía del autor.

\section{Los cuyos: obras de los antiguos y residencias de los dueños}

Para comenzar creo importante contextualizar, aunque sea brevemente, la población a la que me voy a referir en las siguientes páginas. ${ }^{8}$ Nunkiní (figura 3)

${ }^{7} \mathrm{H}$-men es el nombre que reciben entre los mayas peninsulares los especialistas rituales. El sufijo $-o$ 'ob se emplea en el idioma maya yucateco para indicar el plural. En el caso que nos ocupa, por ejemplo, h-men sería el singular de h-meno'ob.

8 Todos los datos etnográficos que presento a lo largo del presente escrito son fruto de mis estancias en la población de Nunkiní, donde he realizado trabajo de campo desde el año 2006. 
es un asentamiento añejo, cuya existencia data desde mucho tiempo antes de que los españoles hicieran su arribo a tierras peninsulares. Así, en la época prehispánica, después de la diáspora acontecida en Mayapán a mediados del siglo xv a raíz de su destrucción y abandono, "nuestra" localidad se encontraba bajo la tutela del halach uinic que residía en el poblado de Calkiní, la que era capital de la provincia de los Ah Canul (Quezada, 1993: 32; Okoshi, 2009: 13-18), tal y como en la actualidad ejerce el mismo estatus en el municipio que lleva su nombre. Esta longevidad quizá sea la explicación más certera para justificar que la presencia de vestigios arqueológicos sea tan nutrida en todo el territorio ejidal de Nunkiní, incluyendo aquí a los espacios residenciales (el propio pueblo), las parcelas de cultivo y el "monte" comunitario que lo circunvala (tierras ejidales), del cual buena parte de la población local obtiene su sustento. En definitiva, no existe espacio habitado, trabajado o "agreste" en todo Nunkiní en el que no se puedan ubicar al menos uno o varios montículos con restos arqueológicos, hasta el punto de que los vecinos elevan su número por encima de cincuenta.

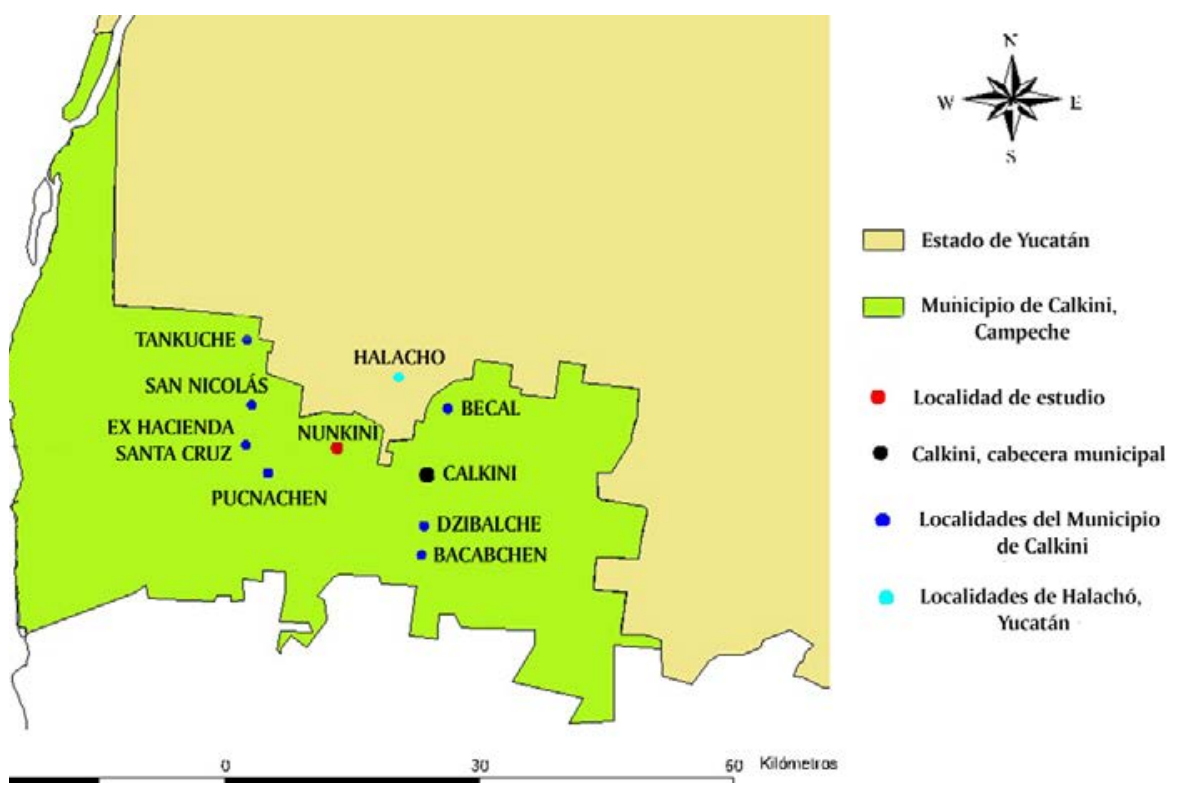

Fıgura 3. Nunkiní, Municipio de Calkiní, Campeche. Autor Miguel Ángel Pinkus Rendón.

El reiterado interactuar de los humanos con estos accidentes del paisaje ha producido cierta familiaridad de aquellos hacia éstos, la cual se observa, por ejemplo, en el hecho de que la gran mayoría de los cuyos poseen un nombre específico que es reconocido por la inmensa mayoría de los vecinos de la localidad. Dichos nombres, a decir de los informantes, "vienen de antiguo", pues nadie 
recuerda ni cómo ni cuándo los adquirieron. La onomástica de los cuyos suele tener relación con algún rasgo característico del entorno natural que les rodea (caso de los montículos nombrados como kaká pak'aal o kaká na'xaán) ${ }^{9}$ con la fisonomía de la propia construcción (chéelpak o Xkamayamúul) ${ }^{10}$ o con algún fenómeno extraordinario que periódicamente acontece en ellos (Xbeech'ilá o Chen t'eel). ${ }^{11}$ Además, dado lo homogéneo del paisaje selvático peninsular, los nombres de los cuyos se emplean asiduamente en el transcurso de las conversaciones que mantienen los vecinos como puntos de referencia espacial que permiten situar a él o los interlocutores sobre el rumbo preciso del ejido del que se está hablando. Por ejemplo, resulta bastante frecuente que un campesino designe el lugar donde se encuentra ubicada su milpa o rancho recurriendo al nombre del cuyo que se halla más cercano. También los grupos de cazadores emplean cotidianamente durante sus charlas de preparación de las batidas los nombres de los distintos cuyos que se ubican en los rumbos del ejido por los que planean adentrarse en busca de venados.

Pero además de los usos eminentemente prácticos que tiene el conocimiento popular de los nombres de los vestigios, éstos son reverenciados y temidos en función al papel que desempeñan como contenedores de un conglomerado de entidades poderosas que genéricamente reciben el apelativo de yumtzilo'ob, el cual se podría traducir tanto por "dueños" como por "patronos" (Villa Rojas, 1985: 174). ${ }^{12}$ Y es que, en la cosmovisión de los indígenas de la Península, como en la de la totalidad de poblaciones amerindias, todo lo que existe sobre la tierra posee un dueño: "disponer del agua de un cenote, de la flora y fauna del monte, explotar un vestigio prehispánico, todo requiere pedir permiso a su dueño” (Quintal, 2003b: 285). En todos los casos, al igual que los espacios donde se alojan, el

\footnotetext{
${ }^{9}$ Estos dos nombres, respectivamente, hacen referencia a sendos cuyos: el primero denominado "Naranja agria” porque cerca de él se ubica un árbol que produce esta variedad de cítrico, y el segundo es el llamado "Lugar de guano", porque sobre él crecen varias palmas de esta variedad.

${ }^{10}$ El primer nombre se puede traducir como "Pared arco iris" debido a que en uno de los muros de la construcción se pueden observar todavía los restos de varios colores. El segundo ha sido traducido como "Cuatro cerros" y hace referencia a un espacio en el que se levantan cuatro grandes montículos.

11 El primer nombre se traduce como "Canto de codorniz", pues varios informantes señalan que algunas noches se puede escuchar ese sonido salir del cuyo, mientras que el segundo es "Pozo gallo", porque el cuyo se encuentra justo detrás de un pozo donde a la media noche se escucha el canto de esta ave.

${ }^{12}$ Respecto al empleo del término Yumtzil, Bruce Love subraya su carácter genérico al apuntar que "it is a generic term for the gods and protectors, and not a specific class or type of god" (2011: 136). De igual forma, en su clásica etnografía sobre los mayas del poblado de Tusik (Quintana Roo), Alfonso Villa Rojas registró el nombre genérico de Yumtzilob para señalar a los diversos "dioses y espíritus paganos" relacionados con la agricultura, a los cuales los mayas "guardan una mayor devoción” (1978: 288). Bajo este rubro había tres grandes grupos de deidades, diferenciados en función de sus atributos y funciones: "los balamob, que tienen a su cargo la protección de milpas, hombres y pueblos; los kuilob $k a x o b$, que vigilan y protegen los montes; y los chacob, que manejan las nubes y reparten las lluvias" (ibidem). A pesar de la distancia geográfica y temporal que separa estos datos y los que yo he podido recopilar en Nunkiní desde 2006, existe una concordancia sorprendente entre ellos.
} 
origen que la cosmogonía local concede a esta amalgama de seres sobrenaturales se halla profundamente enraizado en un pasado muy remoto de carácter mítico conformado, según varios informantes, por dos épocas previas a la actual. ${ }^{13} \mathrm{Al}$ respecto, la tradición oral de Nunkiní especifica que estas dos edades estuvieron habitadas por sendas humanidades diferentes, las cuales fueron destruidas a su conclusión. En la primera época sobre la tierra vivieron los p'uso'ob ${ }^{14}$ o "enanos corcovados", quienes fueron destruidos por el diluvio y construyeron los cuyos más grandes y poderosos que se encuentran en la actualidad. La segunda etapa sería la de "los antiguos mayas", ${ }^{15}$ autores de los montículos de menor tamaño, y sobre los que poco o nada se sabe más allá de que "acabaron cuando llegaron los ts'uulo'ob”. No obstante, debo aclarar que en Nunkiní el conocimiento sobre esta diferenciación entre edades del mundo y humanidades no está generalizado entre todos los vecinos. ${ }^{16}$ Algunos informantes desconocen esta concepción cíclica (y apocalíptica) de la historia, y unifican a todos los habitantes del pasado empleando el genérico "los antiguos" o uchbe'en uinico'ob, sin por ello dejar de adjudicarles ciertas características extraordinarias y sobrehumanas, como sus poderes mágicos y la capacidad que tenían para poder labrar y mover con suma facilidad piedras de gran tamaño, lo que explicaría que hubiesen sido capaces de levantar los enormes templos y pirámides que hoy en día salpican la planicie yucateca.

Sin embargo, y a pesar de las destrucciones acontecidas, las antiguas humanidades no han desaparecido del todo, sino que mantienen una importante presencia en la actualidad, la cual se imagina como la tercera etapa del mundo. Según la opinión generalizada de mis informantes, las entidades poderosas que habitan el interior de los cuyos son consideradas "las primeras personas"; ${ }^{17}$ esto

${ }^{13}$ Las etnografías del área peninsular nos hablan de una creencia generalizada entre los mayas peninsulares en una historia cíclica del mundo, conformada por entre tres y cinco etapas distintas con sus respectivas humanidades. Al respecto véanse los textos de J. E. Thompson (1975: 404-410) o de A. Villa Rojas (1978: 436-442). Una síntesis e interpretación de conjunto sobre la concepción cíclica de la historia por parte de los indígenas asentados en la Península la encontramos en el ensayo de Manuel Gutiérrez Estévez, "Mayas y mayeros: los antepasados como otros" (1992a: 426-432).

14 Según el Diccionario maya-español dirigido por Barrera Vásquez, el término p’us quiere decir "corcovado", pero también remite a unos "hombrecillos corcovados que se mencionan en la mitología de los mayas”, tanto de Belice como de Yucatán (2001: 703-704).

15 Todos los textos que aparezcan entrecomillados y en letras cursivas son citas textuales extraídas de las cientos de conversaciones y entrevistas mantenidas con los habitantes de Nunkiní durante los últimos siete años.

${ }^{16}$ Como mencioné, entre las poblaciones nativas de Yucatán no se encuentra una única versión sobre la historia mítica del mundo y las sucesivas edades que se fueron sucediendo en él hasta el presente. Por ejemplo, y a diferencia de lo registrado en Nunkiní, Allan F. Burns menciona que los mayas yucatecos “creen profundamente que nos encontramos ahora en la cuarta creación”, siendo la inmediatamente anterior a la actual la que habitaron los p'uso'ob (1995: 34).

17 La creencia de que los sitios arqueológicos sirven de morada a ciertas entidades sagradas vinculadas al pasado no es exclusiva de los mayas peninsulares y se encuentra presente en las cosmologías de muchas poblaciones indígenas mesoamericanas. Los lacandones de Chiapas, por ejemplo, 
es, son los restos de esas primeras humanidades, especialmente de los enanos corcovados, que fueron destruidas por Dios o "el Padre Jehová", mediante un diluvio y "la quema" respectivamente. ${ }^{18}$ Sin embargo, gracias a sus poderes mágicos, éstos antiguos habitantes del mundo pudieron sobrevivir tanto al agua como al fuego, gracias a que sus espíritus quedaron encantados y ocultos en el interior de lo que habían sido sus casas, después de que las hubieran sepultado bajo montañas de piedras para protegerlas, dándoles el aspecto que hoy día presentan los cuyos. En estos términos refería un vecino de Nunkiní su visión acerca de las características poderosas que poseían "los antiguos":

todos tienen poderes, todos. Porque cada uno tuvo más de 400 o 600 años o más. Un señor que vive los 200, o 300, o los 400 años, mare, es que hay cosas que ver, está poderoso así. Es igualito al Dios, que el Cristo, tienen poderes, como pasó con leti, como lo digo, con Sansón [...] esos de antes sí tienen poderes. Pienso que todos los antiguos así son. ${ }^{19}$

En virtud a estos poderes, "los antiguos", al ser avisados por "el padre Jehová" de la proximidad de su extinción, pudieron mover y amontonar las grandes cantidades de piedras que hoy conforman los cuyos. De esa forma lograron ocultar sus casas, palacios y templos, en los cuales han perdurado hasta nuestros días. En base a estas creencias, los nunkinienses consideran que debajo de las aglomeraciones de piedras que salpican todo el territorio de su población se encuentran intactas las viviendas de "los antiguos", las cuales son iguales e incluso más lujosas que las que se aprecian en la actualidad en Uxmal o Chichén Itza. En virtud a su condición de h-men, don Nemesio Aké me explicó con detalle la forma en que viven los dueños bajo los cuyos:

sostienen que Yaxchilán es "el centro del mundo", pues en un pasado mítico allí fijó su morada terrestre el dios creador, Hach Ak Yum, y en el presente "cada miembro de la familia celeste tiene allí su residencia" (Marion Singer, 2000: 46). Pero no sólo las etnias mayances reservan un lugar importante en sus cosmovisiones a los vestigios del pasado. Entre los nahuas de Chicontepec, en la Huasteca veracruzana, los restos arqueológicos (tepetzacualli) son tenidos también por "sitios sagrados", al ser considerados las "moradas de los ancestros" (F. Báez-Jorge y A. Gómez Martínez, 2000: 86). También para los zoque-popolucas del estado de Veracruz las "ruinas antiguas y lugares donde habitaron los antepasados" (además de los cerros, las zanjas, los manantiales, los ojos de agua, las cascadas y otros lugares de la naturaleza) son espacios donde moran los chaneques, una suerte de "dueño" de los animales a los que pescadores y cazadores han de solicitar permiso antes de salir en busca de sus presas (García Valencia et al., 2003: 122-123).

${ }^{18}$ Algunos informantes han hecho referencia a una "quema" como el medio por el cual Dios acabó con una de las humanidades anteriores a la actual. Así me lo relataba un campesino: "esos antiguos mayas, eso después del Cristo, del padre Jehová, anda el mundo, así creo yo [...] porque el padre Jehová vino el diluvio, vino la quema. Primero vinieron la quema, quemaron todo, los antiguos mayas hicieron sus casas bajo la piedra que dicen chultún, allá se metieron todos y se defendieron de la quema. Después vino el agua, donde hicieron el arca de Noe y así terminaron los antiguos mayas" (Don Felipe Naal, Nunkiní, noviembre de 2007).

${ }^{19}$ Testimonio ofrecido por don Felipe Naal. Nunkiní, Campeche, diciembre de 2009. 
Nos dicen que cuando se acabaron (los antiguos) que así como está esta casa (se refiere a su vivienda de madera y barro), si lo hacen se cae. Por eso pura piedra labrada hacen sus casas, sus mesas, sus sillas: está muy bonito así. [...] Todo lo que tenemos aquí, tenemos vasos, platos, todo así, también ellos tienen. Si lo llegas a ver: tenemos televisión, el estéreo [...] todo eso lo tienen en su casa debajo de la tierra, en los cuyos. Si escarbamos sacamos todo eso que es de ellos, de los antiguos.

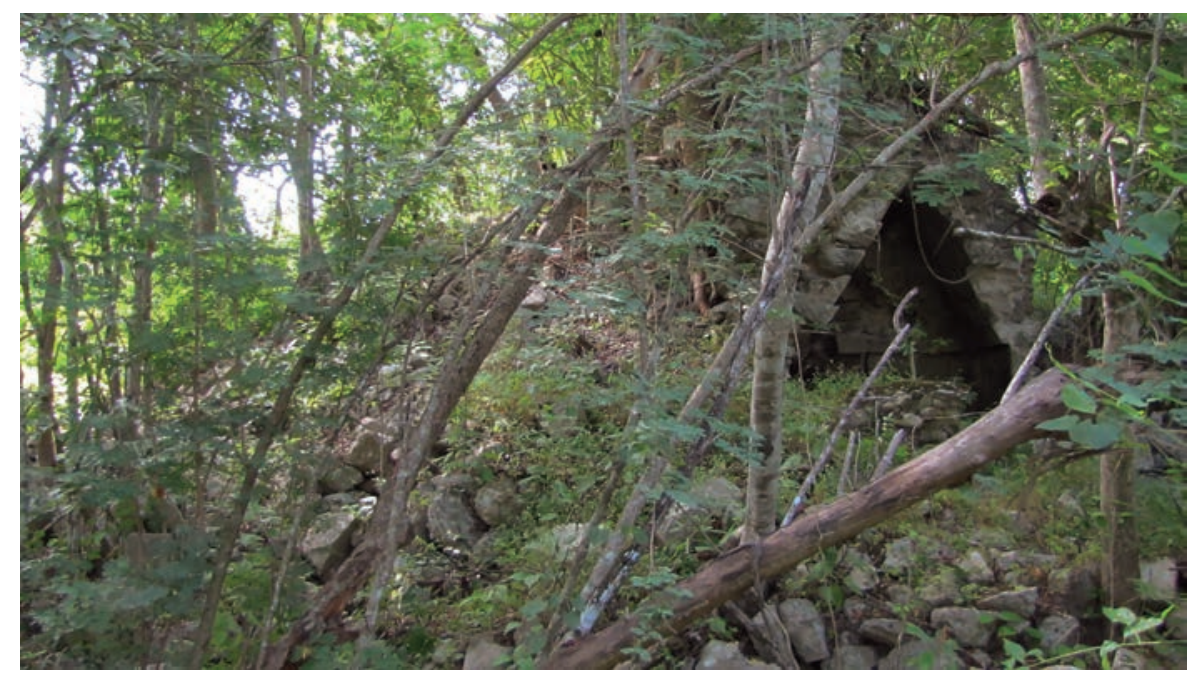

Figura 4. Cuyo semiderruido que permite apreciar parte de la bóveda del edificio que resguarda en su interior. Fotografía realizada por el autor.

Situándonos en el presente inmediato, toca ahora dilucidar cómo caracterizan los habitantes de Nunkiní a los actuales moradores de los vestigios arqueológicos. Uno de los nombres que los habitantes de Nunkiní habitualmente les dan a estas entidades poderosas vinculadas con el pasado es el de aluxes, aunque también resulta frecuente que se refieran a ellas empleando el apelativo genérico de balamo’ob, o más específicamente balamik'áax (“dueño del monte”) o balmikaká (literalmente "dueño del cuyo"). Tanto en la literatura antropológica de la región como en alguno de los testimonios recabados existe cierta confusión respecto a si nos encontramos ante una única entidad de carácter polinominal que recibe distintos nombres (todos ellos sinónimos) dependiendo de los espacios en los que se presenta y actúa, o si, por el contrario, nos hallamos ante personajes distintos que poseen atribuciones, personalidades y campos de acción bien delimitados. ${ }^{20}$

${ }^{20}$ Gutiérrez Estévez (1992a: 436-437) ilustra a la perfección en uno de sus trabajos este debate entre las atribuciones que comparten aluxes, balames y tatabalames en distintas partes de la Penín- 
En lo personal, y a raíz de las diversas evidencias etnográficas recabadas en Nunkiní, me inclino más hacia esta última opción, al menos en lo que respecta a los aluxes y a los balames; ya que parece ser que bajo este último nombre se cobijan otros "dueños" de la naturaleza, como Kalam Tunich, Oxkantziyumen o el bacab. Si bien es cierto que aluxes y balames comparten ciertas características que nos permiten identificarlos como entidades sagradas, como el hecho de residir en el interior de los cuyos, estar vinculados con los espíritus encantados de "los antiguos", o el ser personajes conformados de puro viento y, por ende, invisibles e intangibles para la mayoría de las personas; también lo es que contamos con varias descripciones que dejan entrever diferencias importantes entre ambas entidades en relación a varios aspectos. ${ }^{21}$ Una de ellas sería la apariencia externa que exhibe cada uno de ellos en las ocasiones en que han podido ser vistos por los humanos. Otra diferencia a considerar sería la periodicidad con que se aparecen ante los mortales, pues mientras los relatos de historias y sucedidos ${ }^{22}$ que refieren encuentros entre vecinos de la localidad (con nombres y apellidos) y aluxes abundan, los que tienen como protagonistas a los balamo'ob resultan por demás escasos. Además, otro aspecto a considerar son las notables diferencias que presentan en su fisonomía los aluxes respecto a los balames, mismas que podrían estar insinuando una marcada diferencia de jerarquía entre ambos númenes. Pero antes de sacar conclusiones voy a ceder de nuevo la palabra a otro de mis informantes para conocer la descripción que éste hace de un alux, la cual contiene elementos que podríamos considerar representativos de este personaje en todo el ámbito peninsular:

[los aluxes] son chan personas chiquititas, como chamaquitos de 4 o 5 años. Pero no como estamos nosotros, sino que de puro viento, así son. Hay que están gordos y hay que no. Algunos van desnuditos. Otros visten como los antiguos [...] en su cabeza llevan su sombrero grande de paja, su camisa blanca, su sabucán; su pantalón está corto, así, por la rodilla, y llevan su tabixaná. ${ }^{23}$

sula de Yucatán, y sobre si estos nombres son sinónimos o, por el contrario, remiten a entidades diferentes.

${ }^{21}$ Respecto a este debate en torno a las distinciones entre las deidades nativas que se agrupan bajo el genérico yumtzilo'ob y la dificultad que existe (al menos para los que no somos mayas) a la hora de diferenciarlas, cabe mencionar que el propio Villa Rojas menciona que "los nativos sólo tienen ideas vagas respecto a las cualidades que distinguen entre sí a las diversas deidades que abarca el sector de los yumtzilob" (1978: 289).

${ }^{22}$ La historia y el sucedido son dos variedades de conversación (tzicbal) muy habituales entre los mayas yucatecos. Ambas remiten a sucesos tenidos como verídicos pero que en el caso de la historia ocurrieron en un pasado muy antiguo, de carácter mítico, que resulta imposible fechar (Burns, 1995: 22). En los sucedidos (o ejemplos), por el contrario, el narrador refiere un suceso más cercano en el tiempo y que basa su veracidad en el hecho de que sus protagonistas son mencionados durante el relato con sus nombres y circunstancias particulares para que puedan ser identificados por el auditorio. No es infrecuente que los sucedidos remitan a una transgresión del orden natural o moral y den cuenta del castigo que por parte de las entidades sobrenaturales ello ocasionó al transgresor (Gutiérrez, 1982).

${ }^{23}$ Relato ofrecido por don José Chí. Nunkiní, Campeche, febrero de 2012. 
Como ya había adelantado, los balamo'ob resultan mucho más escurridizos que los aluxes y sólo en muy contadas ocasiones se han dejado ver ante los ojos humanos. Lo anterior se debe a varios factores: en primer lugar a que sus moradas, a diferencia de las de los aluxes, se sitúan bajo los cuyos de mayor tamaño ubicados en los manchones de selva tropical que todavía sobreviven en las afueras de la población. Lógicamente, esta lejanía física respecto a los espacios habitados por los humanos hace más difícil su avistamiento, tal y como a la inversa sucede con los aluxes, quienes suelen residir en los pequeños cuyos que todavía existen dentro de Nunkiní o junto a las parcelas de cultivo. Ello ocasiona que cada poco tiempo algún vecino asegure haberlos visto deambular por calles y solares, o haya escuchado sus silbidos mientras laboraba en su milpa. Además, mientras que a los aluxes se les califica de "bromistas" o "traviesos" y se les asigna el papel de "cuidadores" de los espacios humanos, como milpas, huertos hortícolas, corrales, patios y casas; los balamo'ob son considerados los auténticos "dueños" y "señores" del monte (de ahí que sean nombrados yumilika'ax), a los que el campesino teme y debe solicitar permiso para labrar el campo y posteriormente ofrecer los primeros frutos de la cosecha. ${ }^{24}$ Esto les confiere un mayor rango dentro del panteón local, pues tienen asignadas tareas tan importantes como el cuidado de la foresta donde los hombres obtienen su sustento y de los animales que la habitan. Don Gonzalo, un h-men de la población ya fallecido, aseguraba que ver a los balames resulta del todo imposible para los humanos debido a que:

viven en los cuyos. Mare, no lo dejan que nadie los vea porque son vientos... ahí lo oyes los ruidos, menos que los veas, no lo dejan que lo veas. Pero sí los oyes. Allá dentro de los cuyos están sus casas, esos son encantados ya (se) volvieron así como espíritus allá. Los antiguos los pusieron allá por eso se volvieron como el viento, se escuchan ruidos, cosas, ellos que están pasando y no los ves. Que los veas no los ves, así es. ${ }^{25}$

En otras palabras: resultan demasiado poderosos para que puedan ser visto por los hombres. Aun así, he podido recopilar unos pocos relatos que dan cuenta del encuentro entre hombres y estas divinidades nativas. En ellos varios detalles se encargan de remarcar la mayor jerarquía de los balames respecto a los aluxes, pues aunque ambos guardan bastantes similitudes en lo que a sus atuendos se refiere (que no es otro que el vestían los indígenas peninsulares hasta principios del siglo

\footnotetext{
${ }^{24}$ En su folclórico retrato de la cosmología de los mayas de Yucatán, Renán Irigoyen califica al balam como "el señor del campo" y lo señala como la figura a la que los campesinos deben ofrendar en busca de permiso para cultivar sus milpas (1976: 21). Por su parte, para los mayas de Quintana Roo, los balamo'ob son los encargados de cuidar los pueblos (balam-cahob) y las milpas (balam-col), por lo que cada noche se estacionan "en cada una de las cuatro entradas [...] (para) impedir el paso de las fieras del monte y, principalmente, de los espíritus y "aires" malignos que vengan en busca de víctimas" (Villa Rojas, 1978: 289-290).

${ }^{25}$ Relato ofrecido por don Gonzalo Chan Uk. Nunkiní, Campeche, noviembre de 2009.
} 
$\mathrm{xx})$, no ocurre lo mismo con su edad y estatura. Y es que los balames, a diferencia de los aluxes, cuando aparecen adoptando forma humana lo hacen siempre como ancianos de gran estatura, lo que lleva a algunos informantes a calificarlos como "padres de los aluxitos”. Así los describió un vecino de Nunkiní al relatarme una historia antigua que tiene como protagonistas a tres vecinas del pueblo que recolectaban hojas de una planta de chaya que crecía entre las piedras de un gran cuyo:

encontraron a un señor de pelo blanco, vestido blanco, así, que estaba sentado en una de las piedras del cuyo que les pregunto si eran ellas las que estaban cosechando su chaya. Ellas se asustaron un poco y contestaron al señor que sí, pero el señor no las regañó, sólo las dijo que cosecharan y se fueran. Cuando se volvieron a mirar al señor éste ya no estaba [...] era el "Dueño" del cuyo, ya no es alux o es alux más viejo, su papá de ellos así [...] porque hasta su barba blanca tiene. Ya es Señor del Monte, es el que cuida los montes, balmikaax le decimos. ${ }^{26}$

A pesar de estas diferencias físicas (estatura, edad, cabello blanco), ambas entidades son vistas como poderosas y comparten ciertas características que señalan su condición numinosa. Ya sea como dueños o como guardianes, balames y aluxes poseen una influencia determinante en el éxito o en el fracaso de las diferentes actividades productivas de los hombres y, por consiguiente, éstos deben dedicarles cada año ciertos rituales de carácter individual y familiar en pos de obtener licencia y protección respectivamente. En caso de no hacerlo, estas entidades se mostrarán coléricas y no dudarán en castigar con el envío de una enfermedad que desencadenará calentura, vómitos y diarrea en algún familiar del despistado o egoísta cabeza de familia, habitualmente al menor de sus hijos. ${ }^{27}$ El remedio a este súbito padecimiento escapa a los conocimientos de los galenos occidentales, pues los pequeños únicamente recuperaran su salud cuando sus progenitores los lleven a consultar con alguno de los especialistas rituales del pueblo. Éstos no tardan en descubrir, tras invocar a "los antiguos", rezar y consultar su saastún (o "piedra de vidrio"), que el problema no radica en el cuerpo del enfermo. En la mayoría de los casos la aflicción es una suerte de recordatorio por parte de los dueños para que los hombres cumplan con sus obligaciones rituales hacia ellos, quienes les permiten vivir y trabajar sobre un territorio que no les pertenece. ${ }^{28}$

\footnotetext{
${ }^{26}$ Relato ofrecido por don Pedro Suárez Chi, Nunkiní, Campeche, junio 2006. Esta descripción del balam parece contradecir la que ofreció un informante de Villa Rojas que vio a un yumtzilo'ob al adentrarse a una cueva, pues dice que era un hombre pero "no parecía viejo; tenía los cabellos negros" (op. cit., 289). Por el contrario, guarda varias similitudes con la de los tatabalanes, que son ancianos de cabellos blancos que viste como "los antiguos" (también de blanco) y cuya función es proteger pueblos y milpas, por lo que se les denomina "dueños" (Redfield y Villa Rojas, 1964: 114-167).

${ }^{27}$ Así sucede porque los pequeños son considerados personas más débiles y por tanto susceptibles de ser afectadas más fácilmente por algún viento enviado por el dueño agraviado. Macha’an es el nombre que reciben aquellas enfermedades que son enviadas por las divinidades a modo de castigo.

${ }^{28}$ En este sentido, los distintos dueños de la naturaleza pueden ser vistos como guardianes de una parte del orden moral de la comunidad (Ruz, 2002b: 333 y ss.); aquel que se sustenta en la re-
} 
Como dice don Gilberto, un campesino de 77 años, "a cada rato nos están recordando [los "dueños"] que acá estamos de prestado, porque cada cosa que ves tiene su dueño. Cuando vas a hacer tu milpa, tienes que pedir permiso, sino vas a lastimar tu pie con el machete y pura cascabel vas a ver" ${ }^{29} \mathrm{Y}$ precisamente porque esos "dueños" permiten, propician, guardan y favorecen los frutos que obtienen los hombres de su trabajo, éstos se encuentran en la obligación moral de reintegrarles su ayuda y protección al menos una vez al año, mediante la entrega puntual y pautada de ciertos productos propios, en su mayoría, de la flora y fauna mesoamericana. Que mejor para contentar a deidades netamente amerindias que alimentarlas con productos originarios de las tierra sobre las que señorean, tales como maíz, frijol, pepita de calabaza, tabaco, cacao o licor del árbol balché. A través de un conjunto de rituales de carácter familiar, y muy similares tanto en su forma como en su función, denominados hanlikool, hanlisolar, uklikool o $u$ klisolar ${ }^{30}$ los vecinos de Nunkiní agradecen cíclicamente la ayuda prestada por los "dueños" y renuevan el pacto mítico que subscribieron los hombres con las deidades ancestrales de la tierra y de todo lo que en ella habita.

\section{Especialistas rituales y cuyos: iniciación y rezos}

Antes de ocuparme brevemente de los rituales a los que me acabo de referir, o mejor dicho, del papel que desempeñan los cuyos en ellos, quisiera ofrecer primero algunas someras pinceladas sobre la importancia que tienen los vestigios arqueológicos en otro campo que hasta ahora no había ni siquiera mencionado: el de la iniciación y aprendizaje de los h-meno'ob.

ciprocidad que debe regir las relaciones entre hombres y númenes, en tanto que castigan enviando enfermedades en forma de vientos (' $i k$ ) a quienes, ya sea por omisión voluntaria o involuntaria de sus obligaciones rituales, atentan contra él. Así, los campesinos que inician el trabajo en una parcela de terreno deben para ello solicitar permiso y protección a los dueños originarios de ese terreno mediante la promesa de entregarles periódicamente ciertos alimentos a través de la realización de rituales de hanlikool ("comida de milpa") o uklikool ("bebida de milpa”). Aquellos que falten a su palabra recibirán como castigo la enfermedad, que sufrirán en carne propia o de algún familiar cercano. En su clasificación de las aflicciones mayas peninsulares, Gutiérrez Estévez denominó a la que nos ocupa como "promesa", precisamente por derivarse de las acciones punitivas que emprenden las entidades poderosas hacia los humanos que incumplen sus promesas hacia ellas (2000: 94).

${ }^{29}$ Extracto de conversación mantenida con don Gilberto Chi Collí. Nunkiní, Campeche, febrero 2011.

${ }^{30}$ Los cuatro rituales referidos se podrían traducir respectivamente como "comida de milpa", "comida de patio", "bebida de milpa" y "bebida de patio". La diferencia que existe entre ellos radica en que en los dos últimos únicamente se ofrenda la bebida de maíz y cacao que se conoce como saka' (de ahí que se denomine al ritual "bebida"), mientras que en los dos primeros se realizan ofrendas mucho más complejas y elaboradas, que incluyen, además del saka', doce panes de maíz rellenos de pepita de calabaza y frijol preparado en pib, un pavo adulto guisado con todo y vísceras (tuch), con el que se elabora un caldo al que se le añade masa de maíz (kol) y manteca de cerdo. Para ver las variaciones que presenta este ritual en las distintas áreas indígenas de Campeche véase Mario H. Ruz, 2007. 


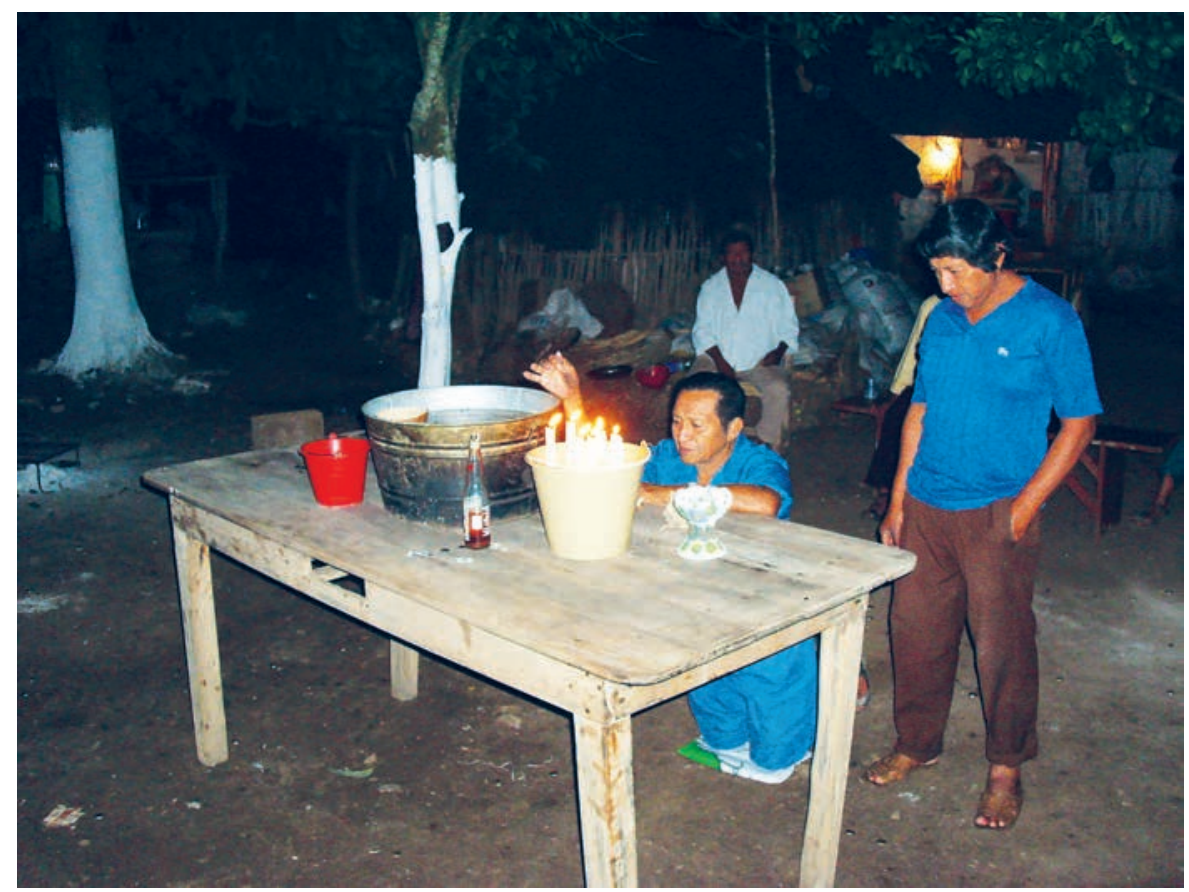

Figura 5. H-men de Nunkiní ofrendando saka' a los dueños, moradores de los cuyos. Fotografía realizada por el autor.

A vuela pluma, conviene señalar que en los cuyos también radican, además de los dueños referidos, los espíritus o almas (pixáno’ob) de los sacerdotes, magos y h-meno' $o b$ ya fallecidos que habitaron sobre la tierra del mayab en los tiempos pretéritos. Éstos y no otros son los "maestros" que reivindican habitualmente los más reputados especialistas rituales contemporáneos como una forma de dotarse, frente a la sociedad local, del aura mística que ha de rodear a cualquier h-men que se precie y, al mismo tiempo, justificar sus atribuciones como intermediarios entre hombres y dueños de la naturaleza en los diferentes rituales que dirigen (tanto en los de curación como en los de ofrendas). ${ }^{31}$ Asimismo, y de forma indirecta, los vínculos cotidianos que estos hombres reivindican con relación al pasado nos permiten identificarlos como una suerte de anclajes de una cierta identidad de marcada especificidad étnica que hunde sus raíces en concepciones cosmogónicas profundamente mesoamericanas, las cuales han so-

${ }^{31} \mathrm{Al}$ respecto, Ella F. Quintal señala que aunque el mecanismo de aprendizaje de los h-meno'ob es terrenal, "éste debe quedar oculto bajo el halo de la dimensión espiritual-mágica, supraterrenal y sagrada del "don" que tiene un origen divino $[\ldots]$ creándose una imagen de sacerdote conocedor de rituales y misterios para dominar a las fuerzas naturales y sobrenaturales que amenazan el bienestar del pueblo y las personas" (2003b: 288). 
brevivido semiocultas y, en muchas casos, enfrentadas a las nuevas formas de vida y pensamiento que han visto la luz a lo largo de las últimas décadas de convulsos, profundos y acelerados cambios socioeconómicos en el seno de las sociedades indígenas peninsulares, a raíz de su forzosa inserción en los procesos económicos neoliberales ligados a la globalización. ${ }^{32}$

Durante el largo proceso de aprendizaje empírico que habrá de realizar como asistente de otro h-men (normalmente su abuelo materno), la persona que desee convertirse en especialista ritual deberá aprender el uso de las plantas medicinales, la preparación del altar, los gestos y acciones a realizar durante los rituales, la forma en que se cocinan las ofrendas y el significado simbólico que poseen sus componentes. Sin embargo, todos los h-meno'ob de Nunkiní reivindican cierto carácter de destino divino en su elección (a raíz del nacimiento con un don) y desempeño, enfatizando el hecho de haber tenido una iniciación de carácter mágico-mística. Lo anterior se pone de manifiesto mediante una variedad de hechos extraordinarios que experimentará, a modo de "llamado", la persona escogida para convertirse en chamán. Quizá el más común de todos ellos sea que antes de cumplir los 8 años ${ }^{33}$ mantendrá diversos encuentros de carácter onírico (y físicos) con los dueños de los cuyos, quienes un día acabarán por conducirle al interior de sus moradas para allí invitarle a comer aquellas ofrendas que los hombres les dan en los rituales que les dedican. Durante esa comida, aluxes y balames procederán a instruir al elegido en los nombres y en la jerarquía de los diferentes cuyos que existen en las inmediaciones de Nunkiní, los cuales habrá de conocer para poder cantar correctamente los rezos de los rituales que dirigirá cuando se haya convertido en $h$-men. ${ }^{34}$

${ }^{32}$ En su pormenorizado recuento de los impactos que la irrupción de la globalización y el sistema económico neoliberal ha producido en las poblaciones nativas peninsulares, Luis Alfonso Ramírez señala que "la pauperización económica y la transformación de las identidades hechos innegables entre los mayas contemporáneos". No obstante, el autor especifica que ello no debe atribuirse exclusivamente a lo acontecido en las dos últimas décadas, sino que se trata de un "proceso de sojuzgamiento cultural y empobrecimiento progresivo que es ya centenario, en donde la desigualdad social y el escamoteo histórico de desarrollo social y étnico nos explican con mayor claridad la situación contemporánea que los procesos a corto plazo" (2006: 76-77). Por su parte, Jesús Lizama (2007), en su etnografía sobre Yaxcabá, ha mostrado cómo los mencionados procesos económicos neoliberales y culturales de carácter global se han dejado sentir con profundas transformaciones en la vida cotidiana de una población indígena concreta.

${ }^{33}$ Además de la iniciación que se realiza ya en vida, en Nunkiní se considera que existen ciertas señales que permiten identificar a los niños que nacen en posesión del "don de Dios" que en un futuro les permitirá desempeñase como $h$-men. Antes de nacer, por ejemplo, a los niños con don se les escuchará llorar en el vientre de sus madres, y, al momento de su llegada al mundo, tendrán algún diente. En referencia a uno de los $h$-meno'ob de Nunkiní se cuenta que, habiendo cumplido ambos requisitos, su abuelo procedió a enterrar 9 granos de cacao en el solar doméstico, los cuales fueron desenterrados uno por uno por el pequeño en cuanto éste hubo adquirido la capacidad de gatear.

${ }^{34} \mathrm{Y}$ es que, como aseguran los h-meno'ob de Nunkiní, en las oraciones que formulan durante los rituales de tipo hanlikool se trata de invitar a los dueños que se alojan al interior de los cuyos ubicados en las cuatro direcciones, para asegurarse de que todos ellos asistan al banquete que los hombres les ofrendan y ninguno se sienta despreciado. Pero no sólo sucede esto en Nunkiní, también en Bacabchén (Campeche), durante el hanlikool "parte primordial de las plegarias es enumerar 
Estos viajes al interior de los vestigios arqueológicos presentan un patrón muy similar en los tres casos concretos que he podido registrar, siendo el común denominador a todos ellos el hecho de que mientras para el niño su estancia en el interior del cuyo duró apenas unas horas, sus progenitores asistieron preocupados a una enfermedad de varios días en los que su hijo permaneció semiinconsciente tirado sobre su hamaca. Se confirma así que el tiempo del interior de los cuyos, que es el tiempo del "otro mundo" habitado por los espíritus y entidades sobrenaturales, y el de la vida ordinaria transcurren y se viven de formas diferentes.

Las primeras relaciones con los dueños se establecen desde la infancia, pero sólo hasta que el candidato a $h$-men es adulto y ha concluido su aprendizaje se producirá el llamado definitivo, también por medio de los sueños o en el transcurso de una enfermedad con episodios febriles. Será en el transcurso de alguno de esos estados de inconsciencia cuando el elegido recibirá la visión que le señalará, con todo lujo de detalles, cuál es y cómo llegar al cuyo donde se oculta la piedra traslúcida o saastún que se convertirá en su principal herramienta de trabajo. ${ }^{35}$ Misma que le permitirá comunicarse y conocer los designios de los residentes sagrados de los restos del pasado, amén de fungir como símbolo indiscutible de su poder, el cual emana, directamente, de los restos de esas humanidades anteriores que habitaron la tierra, hoy convertidos en dueños. Esta piedra "sólo en los cuyos se encuentra porque es el dueño del kaká quien lo guarda allá". Con esta frase lapidaria iniciaba don Gonzalo su relato sobre la forma en que su viejo maestro, don Román Huchí, localizó en un cuyo ubicado a dos kilómetros del pueblo su saastún, tras haber recibido en uno de sus sueños la visita de los h-meno'ob antiguos:

Ya que despertó fácil lo buscó. En su sueño fue que lo vio por donde tenía que ir; cómo era el camino más corto para llegar donde estaba ese cuyo que llaman Xkamayamuul y donde lo iba a buscar [...] todo lo tenían mostrado así. Ya que llegó allá, como lo tiene visto que estaba el saastún, igual lo buscó en el cuyo, no más desenterrarlo hizo y ya estuvo, así, era su suerte. ${ }^{36}$

Constatamos así que el papel que juegan los habitantes de los cuyos es determinante en la formación de los actuales h-meno’ob. Sin embargo, el vínculo entre los especialistas rituales y los vestigios arqueológicos no desaparece una vez que ha concluido su iniciación, sino que, al contrario, se mantiene y fortalece durante

durante las mismas a los kaká, las zonas arqueológicas vecinas, pidiendo a los espíritus que puedan hacerse presentes" (Ruz, 2007: 296).

${ }^{35}$ Siguiendo esta lógica, varios autores han destacado la relación que hay entre el saastún y los distintos dueños y el pasado del cual son originarios. Así, Gutiérrez Estévez señala que "los aluxes dan el poder y el saber al hechicero yucateco; el saastún representa en el ritual ese poder y ese saber" (1992a: 436). Por su parte, Ruz ha incidido en el hecho de que únicamente aquellas personas cuyo destino es convertirse en $h$-men son susceptibles de percibir las señales sobrenaturales que les permitirán hallar la piedra de poder con la cual podrán ejercer sus funciones terapéuticas y rituales (2000: 107).

${ }^{36}$ Testimonio ofrecido por don Gonzalo. Nunkiní, Campeche, diciembre de 2009. 
el resto de sus vidas activas. Y es que, como han referido varios informantes, además de las entidades que ya hemos mencionado, en los cuyos más grandes e importantes también radican los espíritus o pixaano'ob de los h-meno'ob del pasado, quienes son vistos como los más poderosos de cuantos han ejercido. A ellos recurren asiduamente en busca de auxilio y consejo los especialistas rituales contemporáneos: bien sea para saber las plantas con las que preparar un remedio con el que sanar a un paciente; bien para conocer el nombre de los cuyos a los que habrán de cantar durante el rezo de un ritual a desarrollarse fuera de la comunidad; o bien para que los prevengan a tiempo de algún mal que les haya podido enviar un compañero de profesión envidioso de sus éxitos. ${ }^{37} \mathrm{De}$ esta forma tan tajante exponía don Dimencio Aké la importancia de contar con el apoyo de los moradores de los cuyos para desempeñarse como h-men:

Los espíritus, el pixán que decimos, de los h-meno'ob antiguos, los que ya murieron, esos viven dentro del cuyo que se llama X-kamayamul. Son los que me dicen en mi sueño qué rezo voy a tener que usar para que queden bien los que van a llegar a la casa al otro día; me dice como es el medicina, cómo están las plantas, así ya lo preparo todo para cuando llegan las gentes con sus dolores. Listo, ya estuvo, con eso queda bien la persona. ${ }^{38}$

Otra muestra de la importancia que mantienen los cuyos en la vida de los h-meno'ob para que éstos puedan alcanzar el éxito en sus curaciones y hagan llegar a los dueños las ofrendas que las familias les entregan con motivo de los rituales de hanlikool o uklikool es que, todas las noches previas a los martes y viernes (los días “de hechizo" en que trabajan los h-meno'ob), éstos se encomiendan al espíritu o pixán de su maestro y antecesores. Lo anterior lo hacen mediante un rezo silencioso y privado que pronuncian antes de echarse a dormir sobre su hamaca. Previamente prenderán una veladora en el altar doméstico y colocarán junto a ella el saastún y, formando una cruz, las espinas de pescado ( $k^{\prime} i^{\prime}$ ixbaak) que utilizan para pinchar, sangrar y extraen los aires del cuerpo de sus pacientes, ${ }^{39}$ las únicas herramientas con que cuentan habitualmente los h-meno'ob de Nunkiní para realizar su trabajo. Una vez colocados estos implementos, el $h$-men procederá a solicitar el auxilio de los pixano'ob de sus antecesores para que, durante el transcurso de sus sueños, éstos le aconsejen acerca de cómo solventar los casos

\footnotetext{
${ }^{37}$ En este sentido, Mercedes de la Garza señala que este rasgo no es exclusivo de los mayas, sino que también entre los nahuas y otros muchos pueblos indígenas mesoamericanos son los antepasados a través de los sueños quienes se encargan de instruir en el arte de curar a los especialistas rituales (1990: 149). En su clásico trabajo sobre medicina en los altos de Chiapas, William Holland enfatiza la trascendencia que para los curanderos tzotziles tienen los sueños con los ancestros como vía de iniciación y conocimiento en su trabajo (1978).

38 Testimonio proporcionado por don Nemesio Aké. Nunkiní, Campeche, noviembre 2009.

${ }^{39}$ Ya desde antes de la llegada de los conquistadores, era costumbre entre los especialistas de la salud extraer sangre de las partes del cuerpo de sus pacientes donde se presentaba el dolor (Landa, 1978: 49). Actualmente, los h-meno'ob pinchan y extraen sangre de aquellos lugares donde se manifiesta el dolor, pues dicen que es ahí donde se aloja el viento que lo provoca.
} 
que recibirá al día siguiente y le protejan de cualquier mal que le pudieran enviar otros h-meno'ob. El hijo menor de uno de los chamanes que ejercen actualmente en Nunkiní me relató, en relación a este ritual privado, que su padre:

$[\ldots]$ antes que va a su hamaca prende su veladora y habla a sus maestros que ya están muertos. Yo así lo tengo pensado: habla a su pixán de ellos en el cuyo grande para que lo digan todo lo que va hacer. Le pide para que le dé todo, está pidiendo la gracia de los antiguos, ellos le dan su poder para que cura, para que haga bien su rezo, para que salga sus trabajos. ${ }^{40}$

Y si este era el testimonio del hijo, su padre describió en los siguientes términos la forma en que recibe ayuda de su antiguo maestro:

[...] la noche de antes de mi trabajo los h-menes antiguos como don Román vienen a verme. En mi sueño es que lo estoy viendo. Bonito lo estoy escuchando que me habla. Dice cómo lo voy a cantar (el rezo), así. Me lo canta a mí para que no lo vaya a olvidar de llamar a todos los dueños; me dice los nombres de todos los cuyos, de los cuyitos también, a todos los que tengo que llamar, así, para que vengan a buscar su comida que estamos entregando. ${ }^{41}$

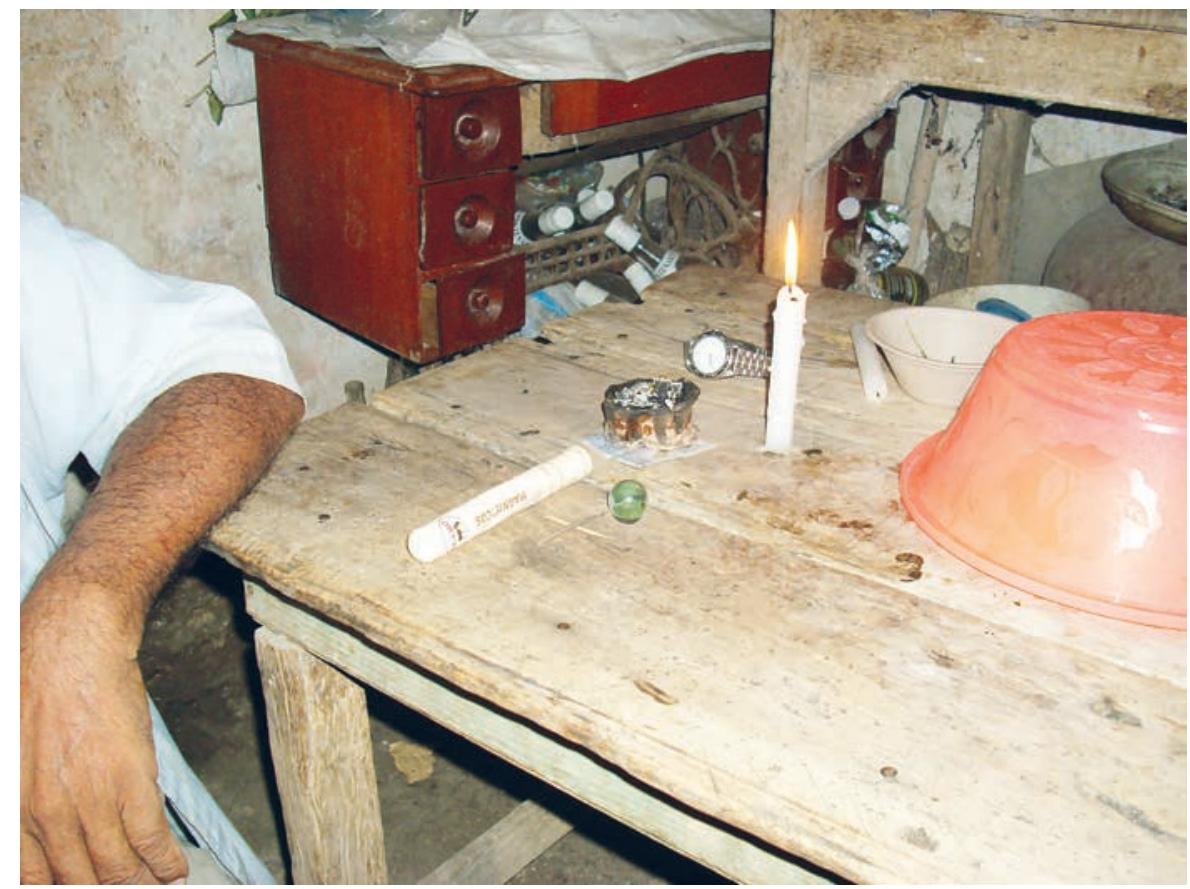

FIGURA 6. La mesa de trabajo de un $h$-men con su instrumental: saastún, veladora y espinas de pescado en forma de cruz. Fotografía realizada por el autor.

40 Testimonio de Santiago Aké. Nunkiní. Campeche, noviembre de 2007.

41 Testimonio de Dimencio Aké. Nunkiní. Campeche, diciembre de 2007. 
Antes de concluir es importante remarcar que la totalidad práctica de los trabajos que llevan a cabo los h-menes están relacionados, en mayor o menor medida, con la acción directa o indirecta de las entidades poderosas que residen en el interior de los cuyos y con las relaciones que establecen hacia ellos los humanos. ${ }^{42}$ Así, por ejemplo, hemos visto en los testimonios precedentes cómo los nombres de los cuyos han de ser correctamente mencionados (en el orden correcto), porque es a sus moradores a quienes los hombres deben dirigir las ofrendas que les entregan en los rituales tipo hanlikool. Por eso, los especialistas rituales que gozan de mayor prestigio entre los habitantes de Nunkiní son aquellos que en sus rezos son capaces de mencionar de memoria el mayor número posible de cuyos, comenzando siempre con los que se ubican en el oriente y terminando en los del sur (en orden inverso a las manecillas del reloj), tomando como punto de referencia la población. Mencionan los vecinos contratantes que así se aseguran de que el $h$-men que han escogido para dirigir el ritual sea capaz de invitar al banquete que con tanta devoción prepararon a todos los santo balmikaax ${ }^{43}$ que señorean sobre los distintos rumbos del territorio comunitario, al tiempo que los alimentos sean convenientemente repartidos entre ellos. Así, concluyen, ninguna de estas entidades poderosas podrá reclamarles y castigarles en el futuro por no haberles entregado la parte de la producción que les corresponde como propietarios originarios que son de la tierra donde viven y trabajan los humanos.

Y si resultan esenciales los cuyos y sus moradores sagrados durante las ceremonias de primicias, no menos lo son en buena parte de los rituales de curación que acometen los h-meno'ob. De las docenas de curaciones que he podido presenciar durante los últimos seis años, un porcentaje elevadísimo de ellas tenían su origen en padecimientos provocados por los aluxes o balames. El principal motivo por el que estos entes enferman se relaciona con algún tipo de castigo en contra de los familiares de aquellos que no cumplen en tiempo y forma (bien por desidia, bien por olvido) sus obligaciones rituales hacia ellos. Otra causa que suele esconderse detrás de las aflicciones provocadas por los dueños, concretamente los aluxes, es el hecho de tener un encuentro fortuito con ellos en el monte, en una calle de la población o en el patio doméstico. Esto no se deben a un intento deliberado de dañar por parte del numen, sino que en vir-

\footnotetext{
${ }^{42}$ No olvidemos que muchas de las aflicciones que padecen los mayas peninsulares tienen su origen en vientos o aires que proceden de los cuyos, en castigos enviados por las diversas deidades cuando no reciben a tiempo o en forma sus ofrendas o cuando las plegarias no han sido formuladas con la devoción adecuada, o por el encuentro con algún "espanto" de los que pueden aparecer en las inmediaciones de los vestigios arqueológicos durante las noches. De esta forma, las ruinas nos remiten a un espacio esencialmente dual en el que, por un lado, los $h$-meno'ob encuentran el instrumento esencial de su poder para sanar y, por otro, son también lugares temidos porque varias enfermedades tienen su origen en ellos (Gutiérrez, 1992a: 437).

${ }^{43}$ En las ocasiones en que los $h$-meno'ob emplean en sus rezos la fórmula castellana "santo" para referirse a los diferentes balamo'ob, lo hacen únicamente como marcador de estatus de estas entidades sobrenaturales, en reconocimiento a sus cualidades poderosas.
} 
tud a su condición de entidad poderosa (como sucede con otras que habitan en la comunidad) de su corporalidad emana un calor que resulta difícil de tolerar para la mayor parte de las personas que se exponen a él y, consecuentemente, acaba derivando en una patología que provocará "calentura", dolor de cabeza y malestar general hasta que el $h$-men santiguie y extraiga "el aire del alux" que se alojó en la cabeza o alguna de las coyunturas del paciente. A esta lista se podrían agregar otras enfermedades, como el "ojo de tierra" que han padecido casi todos los infantes de Nunkiní en algún momento de sus vidas, o los vientos (denominados kaká $i k^{\prime}$ ) que salen del interior de los cerros de piedra lastimando a las personas que se acercaron a ellos sin el debido respeto, con la intención de destruirlos o saquearlos, o a quienes lo hicieron sin haber ofrecido antes o después de su visita una pequeña ofrenda de pom, velas o tabaco, alimentos por excelencia de lo sagrado.

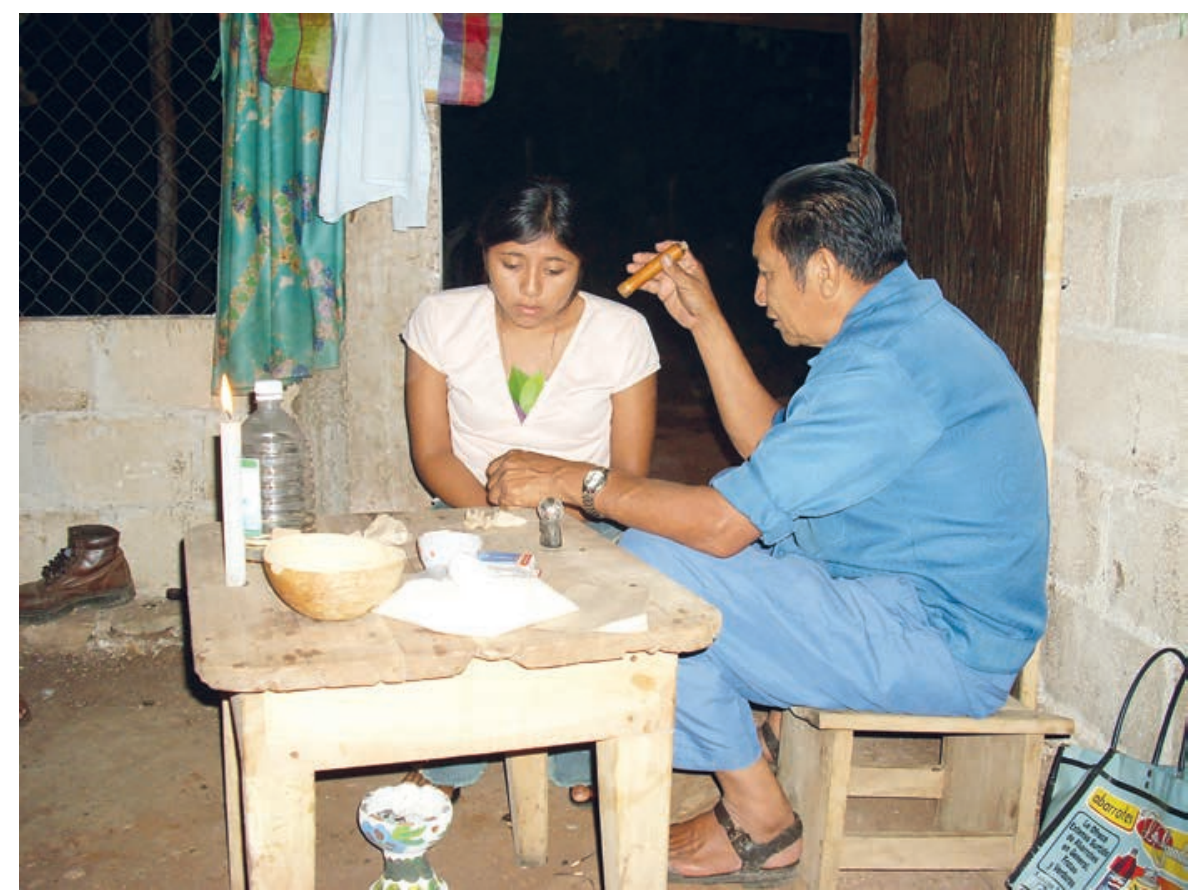

FiguRA 7. Un h-men reza frente a su saastún durante un ritual de curación. Fotografía realizada por el autor.

\section{Colofón: no todo ha sido dicho aún}

Aquí concluyo este somero y desordenado recorrido etnográfico por algunas de las atribuciones que los vecinos de Nunkiní conceden a los restos arqueológicos 
con los que conviven cotidianamente, en tanto que éstos son depositarios de ciertas entidades vinculadas siempre al pasado. No me queda más que volver a incidir en el destacado papel que los cuyos y sus moradores ocupan en la cosmovisión local, que se demuestra evidente a tenor de la centralidad que ocupan en la tradición oral y en el ritual local. De ello he tratado de dar algunas muestras a lo largo del presente escrito. Sin embargo, soy consciente de que algunas cuestiones se han quedado en el tintero.

Uno de los temas que he obviado ha sido una de las formas que, según algunos relatos, adoptan los balamo'ob a la hora de presentarse ante los humanos, que no es otra que la de una serpiente de enormes dimensiones cuyo cuerpo está cubierto de pelos o plumas, y que posee una cara descrita como la de "los reyes que aparecen en las barajas, con sus bigotes y barba". A esta serpiente se le adjudica la capacidad de volar, y su composición, como la de todas las entidades poderosas de los mayas peninsulares, es el viento ('ik). Tal y como ya registrara Manuel Gutiérrez en el ejido de Villa Madero, también en Campeche, ésta y otras serpientes de similares características son las causantes de diversos males y enfermedades, pues, cuando se elevan y surcan los aires, el batir de sus alas provoca en la tierra remolinos de viento que enferman a los hombres y dañan las cosechas (1992b).

Sin duda este ejemplo nos sitúa ante la superposición de dos figuras duales, de procedencia y significados diversos, que han venido a agruparse en tanto que comparten morada bajo los cuyos, dotando así a estos espacios del mismo estatus dual que poseen sus moradores. Por un lado, el balam resulta una suerte de dueño maya de los montes, así como de las milpas y ranchos que en ellos se ubican, quien con su "gracia" permite a los humanos obtener su sustento a través de la explotación de la foresta sobre la que señorea. Pero también encontramos a una serpiente tan grande como dañina para los hombres, pues es generadora de un gran remolino de viento (moson'ik) que enferma y acaba con las milpas. Consecuentemente, no resulta extraño que, en algunos testimonios, los vecinos de Nunkiní la vinculen con Kisín (el nombre que recibe el diablo entre los mayas yucatecos) y con toda una categoría de seres denominados kakasbaal ("malignos"). No en vano todos los ofidios fueron calificados por uno de mis informantes como "mascotas del Diablo". ${ }^{44}$

\footnotetext{
${ }^{44}$ No parecería descabellado responsabilizar a la evangelización católica de la actual asociación que se da entre las serpientes y el diablo. En este sentido, el dominico Francisco Núñez de la Vega ya apuntaba en el siglo xvIII la estrecha relación que tenían estos animales con la iniciación de los especialistas rituales mayas, los cuales, para alcanzar sus conocimientos, debían hacer un "pacto con el Diablo", el cual se aparecía en forma de "un feroz dragón a modo de serpiente, echando fuego por la boca y ojos, y abriéndola se traga al tal discípulo, y lo vuelve a echar por la parte prepostera del cuerpo; y entonces le dice su Maestro que ya está enseñado" (Núñez de la Vega, apud Boccara, 2004: 22-23). En época prehispánica, por el contrario, los mayas veían en las serpientes al "animal sagrado por excelencia, que simboliza (entre otras cosas) la energía generadora del mundo, representando agua, sangre y fecundidad", amén de estar relacionada con las iniciaciones religiosas de los sacerdotes (Garza, 1990: 137).
} 
En relación a estos últimos seres vinculados al mal, tampoco he mencionado, más que de pasada, que los cuyos son también espacios vinculados al mal, pues en ellos pueden aparecer, sobre todo a determinadas horas del día (mediodía y medianoche) y en ciertos días del año (el Viernes Santo o los días de Carnaval), los denominados "espantos" e incluso el mismísimo Demonio. ${ }^{45}$ En relación a los "espantos", estos son entes maléficos, formados también de puro viento, cuyo único cometido pareciera ser el de asustar a los humanos con su mera presencia, provocándoles tras el encuentro enfermedades como el "espanto", que únicamente un h-men puede curar. De nuevo nos hallamos ante una muestra más del círculo que se abre y se cierra en el interior de los cuyos, espacios simbólicos de carácter netamente dual que remiten, indistintamente, a un pasado que sigue condicionando el presente cotidiano. Lo anterior queda perfectamente retratado en una enfermedad que brota de las ruinas en forma de aire y que, gracias al poder y los conocimientos que los moradores de estos lugares otorgan a los h-meno' $o b$, puede ser sanada siguiendo los procedimientos rituales que marca la tradición (que emana de los propios vestigios del pasado).

Por rescatar la idea central que ha venido articulando en estas páginas, me gustaría resaltar el hecho de que los cuyos son en la cosmología maya peninsular espacios vinculados a un pasado remoto de carácter mítico. Un pasado que, lejos de haber desaparecido, se mantiene muy activo en el presente por medio de las entidades poderosas que simbólicamente lo encarnan. Balames y aluxes, dueños de la naturaleza y cuidadores de los espacios domésticos y productivos (milpas, ranchos, solares, etc.) respectivamente, son personajes cuyo origen se remonta a un número variable de épocas pasadas a la que ocupa la humanidad actual, todas ellas concluidas a raíz de sucesivas destrucciones (por fuego, lluvia, conquista). Sin embargo, sus poderes encarnados en la figura de los especialistas rituales contemporáneos los mantienen actuantes en nuestros días. No olvidemos que gracias a los poderes, conocimientos y herramientas que obtienen de sus antecesores radicados en los cuyos, de los que el saastún representa el símbolo principal, los h-meno'ob pueden curar, encontrar objetos, animales y personas extraviadas, comunicarse con los vientos y seres sobrenaturales y, lo que es más importante, mantener el equilibrio cósmico que deriva del correcto y puntual cumplimiento de los pactos de reciprocidad que rigen las relaciones entre hombres y divinidades desde el inicio de los tiempos.

Consecuentemente, los restos del pasado que hoy día se esconden bajo la vegetación selvática de la península yucateca podrían ser vistos como uno de

${ }^{45}$ Algunos autores han recopilado relatos sobre ruinas en los que a determinadas horas del día hacía acto de presencia Kisín adoptando alguna de sus formas más habituales: un hombre trajeado o un gran toro de color negro (Amador Naranjo, 2002: 243-244). Por su parte, en un revelador ensayo, Gutiérrez Estévez traza un paralelismo entre la gran serpiente emplumada de nombre Xkukikán que habita hoy día el interior de algunos restos arqueológicos de la Península y el Anticristo que vendrá al mundo con motivo del Juicio Final para juzgar la lealtad de los mayas yucatecos a la figura de Jesucristo (1992b). 
los cimientos más sólidos de la vertiente mesoamericana de la religiosidad maya peninsular contemporánea. Una religiosidad en continua readecuación en su búsqueda por adaptar, por ejemplo, nuevos métodos de producción como la horticultura y la ganadería a los añejos rituales agrícolas, en origen destinados exclusivamente a las tareas propias de la milpa. Sólo así se entiende que durante el desarrollo de un hanlikool, la jícara del h-men vierta el sagrado saka' (bebida de maíz nuevo con cacao) por igual sobre la milpa de un campesino que en el solar de una vivienda donde opera un negocio de renta de computadoras con Internet. Lo mismo da. Al fin y al cabo, de la permisividad de los yumtzilo'ob dependerá en buena medida el éxito de todas las empresas que decidan acometer los hombres y mujeres mayas sobre esta tierra que, no lo olvidemos, únicamente les ha sido "prestada" por sus dueños originarios.

\section{BIBLIOGRAFÍA}

Álvarez, Cristina

1997 Diccionario etnolingüístico del idioma maya yucateco colonial (vol. III). México: Universidad Nacional Autónoma de México, Instituto de Investigaciones Filológicas, Centro de Estudios Mayas.

Amador Naranjo, Ascensión

2002 “Kisín, el demonio yucateco", Demonio, religión y sociedad entre España y América, Fermín del Pino Díaz (coord.). Madrid: Consejo Superior de Investigaciones Científicas, pp. 239-252.

Báez-Jorge, Félix y Arturo Gómez Martínez

2000 "Los equilibrios del cielo y de la tierra. Cosmovisión de los nahuas de Chicontepec", Desacatos. Revista de Antropología Social, 5: 79-94, Gwennhael Huesca Reyes (ed.). México: Centro de Investigaciones y Estudios Superiores en Antropología Social.

Barabas, Alicia M.

2003 "Introducción: una mirada etnográfica sobre los territorios simbólicos indígenas", Diálogos con el territorio. Simbolizaciones sobre el espacio en las culturas indígenas de México, vol. I, Alicia M. Barabas (coord.). México: Instituto Nacional de Antropología e Historia, pp. 15-36.

Barrera Vásquez, Alfredo (dir.)

2001 Diccionario maya-español, español-maya. México: Editorial Porrúa.

Boccara, Michel

2004 H-Wan Tul, dueño del metnal. Mitología del ganado y del dinero (Los laberintos sonoros. Enciclopedia de la mitología yucateca, tomo IV). París: Editions Ductus \& "Psychanalyse et pratiques sociales" (CNRS-Universités de Picardie et de Paris 7). 
Burns, Allan F.

1995 Una época de milagros. Literatura oral del maya yucateco. Mérida: Universidad Autónoma de Yucatán.

Carrillo y Ancona, Crescencio

1861 "Las ruinas de Yucatán III (el adoratorio de Motul)", El receptorio pintoresco. Miscelánea instructiva y amena. Mérida: Imprenta de José Dolores Espinosa, pp. 297-302.

Ciudad Real, fray Antonio de

1995 Calepino de Motul. Diccionario maya-español, edición de Ramón Arzápalo Marín. México: Universidad Nacional Autónoma de México, Dirección General de Asuntos de Personal Académico / Instituto de Investigaciones Antropológicas.

García Canclini, Nestor

$2001 \quad$ Culturas híbridas. Estrategias para salir y entrar de la modernidad. México: Grijalbo.

García Valencia, Hugo (coord.)

2003 "Espacio sagrado y ritual en Veracruz", Diálogos con el territorio. Simbolizaciones sobre el espacio en las culturas indígenas de México, vol. II, Alicia M. Barabas (coord.). México: Instituto Nacional de Antropología e Historia, pp. 101-159.

Garza, Mercedes de la

1990 Sueño y alucinación en el mundo náhuatl y maya. México: Universidad Nacional Autónoma de México, Instituto de Investigaciones Filológicas, Centro de Estudios Mayas.

Gutiérrez Estévez, Manuel

1982 "Cuento, ejemplo y conversación entre los mayas de Yucatán”, Ethnica. Revista de Antropología, 18 (2): 93-116. Barcelona: Centro Superior de Investigaciones Científicas / Centro de Etnología Peninsular.

1992a "Mayas y "mayeros»: los antepasados como otros", De palabra y obra en el nuevo mundo 1. Imágenes interétnicas, Miguel León-Portilla, Manuel Gutiérrez Estévez, Gary H. Gossen y J. Jorge Klor de Alva (eds.). Madrid: Siglo XXI Editores / Junta de Extremadura, pp. 417-441.

1992b "Alteridad étnica y conciencia moral. El Juicio Final de los mayas yucatecos", De palabra y obra en el Nuevo Mundo 2. Encuentros interétnicos, Manuel Gutiérrez Estévez, Miguel León-Portilla, Gary H. Gossen y J. Jorge Klor de Alva (eds.). Madrid: Siglo XXI Editores / Junta de Extremadura, pp. 295-322.

2000 "La colonización del cuerpo. El otro en las aflicciones mayas yucatecas", Sustentos, aflicciones y postrimerías de los indios de América, Manuel Gutiérrez Estévez (ed.). Madrid: Casa de América, pp. 87-106.

2002 "Cosmovisión dualista de los mayas yucatecos actuales", Religión maya, Mercedes de la Garza Camino y Martha Ilia Nájera Coronado (eds.). Madrid: Editorial Trotta, pp. 265-387. 
Holland, William R.

1978 Medicina maya en los Altos de Chiapas. México: Instituto Nacional Indigenista.

Irigoyen, Renán

1976 Esencia del folklore de Yucatán. Mérida: Ediciones del Gobierno de Yucatán.

Landa, fray Diego de

1978 Relación de las cosas de Yucatán. México: Editorial Porrúa.

Lizama Quijano, Jesús

2007 Estar en el mundo. Procesos culturales, estrategias económicas y dinámicas identitarias entre los mayas yucatecos. México: Centro de Investigaciones y Estudios Superiores en Antropología Social / Editorial Porrúa (Colección Peninsular).

López Austin, Alfredo

1994 Tamoanchan y Tlalocan. México: Fondo de Cultura Económica.

Love, Bruce

2011 "The Gods of Yucatan from A.D. 1560 to 1980", Estudios de Cultura Maya, XXXVII: 123-148, Maricela Ayala y Roberto Romero (eds.). México: Universidad Nacional Autónoma de México, Instituto de Investigaciones Filológicas, Centro de Estudios Mayas.

Lupo, Alessandro

1996 "Síntesis controvertidas. Consideraciones en torno al concepto de sincretismo", Revista de Antropología Social, 5: 11-37. Madrid: Universidad Complutense de Madrid.

Marion Singer, Marie-Odile

2000 "Bajo la sombra de la gran ceiba: la cosmovisión de los lacandones", Desacatos. Revista de Antropología Social, 5: 45-56, Gwennhael Huesca Reyes (ed.). México: Centro de Investigaciones y Estudios Superiores en Antropología Social.

Okoshi Harada, Tsubasa

2009 "Introducción”, Códice de Calkiní. México: Universidad Nacional Autónoma de México, Instituto de Investigaciones Filológicas, Centro de Estudios Mayas, pp. 5-29.

Quezada, Sergio

1993 Pueblos y caciques yucatecos. 1550-1580. México: El Colegio de México.

Quintal, Ella Fanny et al.

2003a "Solares, rumbos y pueblos: organización social de los mayas peninsulares", La comunidad sin límites. La estructura social y comunitaria de los pueblos indígenas de México, vol. I, Saúl Millán y Julieta Valle (coords.). México: Instituto Nacional de Antropología e Historia, pp. 293-382.

2003b “U lu’umil maaya wíniko’ob: la tierra de los mayas”, Diálogos con el territorio. Simbolizaciones sobre el espacio en las culturas indígenas de México, vol. I, Alicia 
M. Barabas (coord.). México: Instituto Nacional de Antropología e Historia, pp. 275-359.

Ramírez Carrillo, Luis Alfonso

2006 "Impacto de la globalización en los mayas yucatecos", Estudios de Cultura Maya, XXVII: 73-97, Mario H. Ruz y Claudia M. Báez (eds.). México: Universidad Nacional Autónoma de México, Instituto de Investigaciones Filológicas, Centro de Estudios Mayas.

Redfiel, Robert y Alfonso Villa Rojas

1964 Chan Kom, a Maya Village. Chicago: University of Chicago Press.

Ruz Sosa, Mario Humberto

2000 "El resplandor de la tradición. Estampas médicas entre los mayas contemporáneos", Sustentos, aflicciones y postrimerías de los indios de América, Manuel Gutiérrez Estévez (ed.). Madrid: Casa de América, pp. 107-136.

2002a "Los mayas peninsulares”, Los mayas peninsulares: un perfil socioeconómico, Mario Humberto Ruz (coord.). México: Universidad Autónoma de México, Instituto de Investigaciones Filológicas, Centro de Estudios Mayas, pp. 1045 .

2002b "Credos que se alejan, religiosidades que se tocan: los mayas contemporáneos”, Religión maya, Mercedes de la Garza Camino y Martha Ilia Nájera (eds.). Madrid: Editorial Trotta, pp. 321-363.

2006 Pueblos indígenas del México contemporáneo. Mayas, vol. 2. México: Comisión Nacional para el Desarrollo de los Pueblos Indígenas / Programa de las Naciones Unidas para el Desarrollo.

Ruz Sosa, Mario Humberto (coord.)

2007 El Campeche maya: atisbos etnográficos. México: Universidad Autónoma de México, Coordinación de Humanidades, Unidad Académica de Ciencias Sociales y Humanidades.

Thompson, J. Eric

1975 Historia y religión de los mayas. México: Siglo XXI.

Villa Rojas, Alfonso

1978 Los elegidos de Dios. Etnografía de los mayas de Quintana Roo. México: Consejo Nacional para la Cultura y las Artes, Dirección General de Publicaciones / Instituto Nacional Indigenista (Presencias, 57).

1985 Estudios etnológicos. Los mayas. México: Universidad Nacional Autónoma de México, Instituto de Investigaciones Antropológicas (Etnología, Serie Antropológica, 38). 